\title{
Picture Exchange Communication System (PECS) dan Communication Apprehension (CA) pada Remaja Tunagrahita Jenjang SD di SLBN Salatiga
}

\author{
Happy Cahyani Sunusi ${ }^{1}$, Chr. Hari Soetjiningsih ${ }^{2}$, A. Ign. Kristijanto ${ }^{3}$ \\ ${ }^{1,2,3}$ Fakultas Psikologi Universitas Kristen Satya Wacana
}

\begin{abstract}
The purpose of this study was to examine the influence of PECS on verbal communication skills skills of adolescent tunagrahita and test the difference of anxiety verbal communication adolescent tunagrahita based on gender. Experimental design for verbal communication skills used Analysis of Covariance with Randomized Completely Block Design (RCBD) based on 6 phases of pre and post test. The subjects of this research was seven elementary students. Data collection used the Measure of Elementary Communication Apprehension (MECA) questionnaire and be analyzed using Covariance Analysis, verbal communication anxiety pre and post test analyzed by Wilxocon and the difference verbal communication anxiety by sex analyzed by Mann Whitney $U$. The results of this study show that PECS can improve verbal communication skills and affect verbal communication anxiety in elementary school adolescent with intellectual disability and also differ based on sex.
\end{abstract}

Keywords: picture exchange communication system; verbal communication ability skill; verbal communication anxiety

\begin{abstract}
Abstrak. Tujuan penelitian ini adalah untuk menguji pengaruh PECS terhadap keterampilan kemampuan komunikasi verbal remaja tunagrahita dan menguji perbedaan kecemasan komunikasi verbal remaja tunagrahita berdasar jenis kelamin. Desain eksperimen untuk data keterampilan komunikasi verbal menggunakan analisis Dwi Ragam dengan rancangan dasar RAK (Rancangan Acak Kelompok) berdasarkan enam tahapan pra dan paska uji. Partisipan penelitian sebanyak tujuh siswa SD. Alat pengumpulan data menggunakan kuesioner Measure of Elementary Communication Apprehension (MECA) selanjutnya menggunakan Analisis Dwi Ragam, uji perbedaan kecemasan komunikasi verbal pra dan paska uji menggunakan uji Wilxocon dan uji perbedaan kecemasan komunikasi verbal berdasar jenis kelamin menggunakan uji Mann Whitney $U$. Hasil yang ditemukan PECS dapat meningkatkan keterampilan komunikasi verbal dan juga kecemasan komunikasi verbal pada remaja tunagrahita jenjang SD berdasar jenis kelamin.
\end{abstract}

Kata kunci: kemampuan komunikasi verbal; penurunan kecemasan komunikasi verbal; picture exchange communication system

Penyandang cacat adalah seseorang yang memiliki kelainan fisik atau mental yang dapat mengganggu atau merupakan rintangan dan hambatan baginya untuk melakukan kegiatan secara layak yang terdiri dari penyandang cacat fisik,

\footnotetext{
${ }^{1}$ Korespondensi mengenai artikel ini dapat melalui: cahyadisunusi@gmail.com
} 
penyandang cacat mental, dan penyandang cacat fisik dan mental (Depkes RI, 2010). Anak-anak yang mengalami keterbatasan atau ketidakmampuan, baik fisik ataupun psikis, baik yang bersifat bawaan ataupun terjadi ketika masa pertumbuhan disebut dengan Anak Berkebutuhan Khusus (ABK) (Hallahan dan Kauffman, 2006).

Salah satu anak berkebutuhan khusus adalah anak dengan keterbelakangan mental, disebut juga dengan tunagrahita. Anak tunagrahita adalah anak yang mempunyai kemampuan intelektual di bawah rata-rata dan ketidakcakapan dalam interaksi sosial (Somantri, 2006). Geniofam (2010) juga menambahkan bahwa tunagrahita adalah anak yang fungsi intelektualnya lamban, memiliki IQ di bawah 70 berdasarkan tes inteligensi baku dan terjadi pada masa perkembangan, yaitu antara masa konsepsi hingga 18 tahun. Menurut Riskesdas tahun 2010 dalam Depkes RI (2014), persentase anak tunagrahita sebesar $0.14 \%$ di Indonesia dan Jawa Tengah menempati urutan kedua setelah DKI Jakarta. Berdasarkan data Balai Pengembangan Pendidikan Khusus Dinas Pendidikan Provinsi Jawa Tengah (BPDIKSUS) tahun 2016, jumlah siswa SLB di Jawa Tengah berjumlah 15.340 anak. Anak jenis ketunaan paling tinggi adalah tunagrahita yang berjumlah 10.102 anak. Di Salatiga, siswa tunagrahita berjumlah 328 siswa.

Salah satu hambatan dalam berkomunikasi adalah hambatan dalam proses penyampaian (sender barries) di mana hambatan ini datang dari pihak komunikator yang kesulitan dalam menyampaikan pesan disebabkan oleh kekurangan penguasaan bahasa, pendidikan, intelektual, dan lainnya yang terdapat dalam diri komunikan dan salah satunya adalah perasaan cemas (Ruslan, 2008). Menurut West \& Turner (2009) kecemasan dalam berkomunikasi (Communication Apprehension) yaitu ketakutan berupa perasaan negatif yang dirasakan individu dalam melakukan komunikasi, biasanya berupa perasaan tegang, gugup ataupun panik ketika melakukan komunikasi. Weiten, Lloyd, Dunn, \& Hammer (2009) juga menambahkan bahwa kecemasan komunikasi adalah ketegangan yang dialami seseorang ketika akan berbicara dengan orang lain, seperti perasaan gugup.

Menurut McCroskey (1984), kecemasan komunikasi memiliki empat tipe, yaitu traitlike communication apprehension, generalized-context communication apprehension, person-group communication apprehension, dan situasional communication apprehension. Lebih lanjut menurut McCroskey (1984), faktor-faktor penyebab kecemasan komunikasi terdiri dari faktor keturunan, faktor lingkungan, faktor reinforcement, faktor situasi komunikasi, faktor penilaian, dan faktor kemahiran kemampuan dan pengalaman.

Fenomena kecemasan dalam berkomunikasi dijumpai pada remaja tunagrahita di SLB Negeri Salatiga yaitu remaja tunagrahita jenjang SD merasa cemas ketika berbicara dengan orang lain khususnya dengan orang yang baru ditemui atau dikenali yang disebabkan oleh kurangnya kepercayaan diri dari remaja tunagrahita untuk memulai percakapan karena kurangnya perbendarahaan kata. Terlihat juga saat remaja tunagrahita berbicara dengan orang lain, mereka tidak melakukan kontak mata, gemetar, gagap ketika berbicara, takut memulai percakapan, dan sering mengulangi kata-kata yang telah diucapkan. Hal ini tidak sesuai dengan tugas perkembangan remaja menurut Santrock (2007) bahwa remaja mulai menunjukkan perkembangan bahasa, seperti adanya peningkatan menganalisis fungsi suatu kata yang berperan dalam 
sebuah kalimat, memahami perbandingan makna antara dua hal yang berbeda, meningkatnya kemauan untuk memahami literatur yang rumit, mengembangkan sebuah ide untuk menyusun sebuah tulisan, dan dapat berbicara dari berbagai variasi kosa kata.

Ada berbagai terapi komunikasi yang bisa diterapkan pada anak tunagrahita, yaitu pertama, Augmentative and Alternative Communication (AAC) (Beukelman \& Mirenda, 2013), terapi penjadwalan kegiatan/dukungan visual (Hart \& Whalon, 2008), dan instruksi berbasis komputer (Bernard-Opitz, Sriram, \& NakhodaSapuan, 2001; Neely, Rispoli, Camargo, Davis, \& Boles, 2013). Salah satu terapi bicara untuk anak tunagrahita adalah terapi Picture Exchange Communication System (PECS) yang merupakan salah satu dari sistem Augmentative and Alternative Communication (AAC) yang digunakan orang berkebutuhan khusus yang memiliki gangguan dalam berkomunikasi untuk menggantikan atau melengkapi kemampuan komunikasi yang terbatas (Bondy \& Frost, 2011). Murwati (2013) juga menambahkan bahwa siswa pengguna PECS adalah mereka yang perkembangan bahasanya tidak berkembang dan mereka tidak berkemauan untuk berkomunikasi dengan orang lain.

Terdapat enam tahapan metode PECS, yaitu, pertama, mengajarkan cara pertukaran nama; kedua, meningkatkan spontanitas; ketiga, membedakan gambar secara bersamaan; keempat, membangun struktur kalimat; kelima, menanggapi “Apa yang kamu inginkan?"; dan keenam, berkomentar dalam menanggapi pertanyaan (Bondy \& Frost, 2011). PECS memiliki kelebihan dibandingkan dengan terapi bicara lainnya, yaitu dirancang untuk mengatasi kurangnya motivasi, mengajarkan untuk memulai bukan mengajarkan menanggapi sebelum memulai, mempunyai tujuan yang jelas dan mudah dipahami karena menggunakan gambar serta tidak memerlukan keterampilan prasyarat untuk menerapkan terapi ini (Bondy \& Frost, 1994; Wallin dalam Murwati, 2013).

Salah satu penelitian yang menggunakan PECS adalah penelitian oleh Cummings, Carr, \& LeBlane (2011) mengemukakan bahwa PECS dapat meningkatkan komunikasi pada anak yang mengalami disabilitas yang dilakukan pada tujuh anak laki-laki yang mengalami gangguan berbahasa, salah satunya yaitu anak tunagrahita. Hasil penelitian tersebut menunjukkan bahwa Alex, anak tunagrahita yang berusia empat tahun mengalami kenaikan persentase setelah dilakukan training PECS dengan total sebesar 51\% yang sebelum dilakukan training PECS nilai persentasenya mendekati $0 \%$.

Oleh karena itu, tujuan penelitian ini adalah pertama, menguji pengaruh PECS terhadap kemampuan komunikasi verbal remaja tunagrahita jenjang SD. Kedua, menguji perbedaan kecemasan komunikasi verbal remaja tunagrahita jenjang SD berdasar jenis kelamin sebelum dan sesudah perlakuan PECS.

Berdasarkan tujuan penelitian di atas, maka hipotesis dalam penelitian ini adalah: pertama, PECS berpengaruh positif terhadap kemampuan komunikasi verbal remaja tunagrahita jenjang SD. Kedua, PECS berpengaruh terhadap kecemasan komunikasi verbal remaja tunagrahita jenjang SD sebelum dan sesudah perlakuan PECS dan berdasar jenis kelamin.

\section{Metode}

Desain eksperimen untuk keterampilan kemampuan komunikasi verbal menggunakan Analysis of Covariance/ANCOVA 
dengan rancangan dasar RAK (Rancangan Acak Kelompok) berdasar hasil nilai pra uji (X) dan paska uji (Y) setiap tahapan perlakuan PECS. Sedangkan untuk perbedaan kecemasan komunikasi verbal menggunakan pretest-posttest design dengan perlakuan PECS yang bertujuan untuk menentukan tingkat kecemasan komunikasi verbal pada remaja tungrahita yang dinilai dua kali yaitu sebelum dan sesudah perlakuan PECS. Penelitian ini melibatkan satu kelompok eksperimen tanpa kelompok kontrol. Prosedur eksperimen PECS dengan enam tahap dilakukan selama empat kali pertemuan berdurasi 60 menit untuk sekali pertemuan.

\section{Partisipan eksperimen}

Partisipan dalam penelitian ini sebanyak tujuh siswa tunagrahita ringan jenjang SD (lima siswa laki-laki dan dua siswi perempuan). Satu orang kelas $\mathrm{V}$ dan enam orang kelas VI dengan kisaran usia 12 - 16 tahun di SLB Negeri Salatiga. Pemilihan partisipan menggunakan teknik non probability sampling dengan cara saturated sampling.

\section{Instrumen penelitian}

Instrumen untuk mengukur kecemasan komunikasi verbal menggunakan skala kecemasan komunikasi verbal MECA (Measure of Elementary Communication Apprehension) (Garrison \& Garrison, 1977). Skala ini bisa digunakan untuk anak disabilitas seperti tunanetra, gangguan emosional, tunarungu, dan retardasi mental.

\section{Analisa data}

Untuk menguji perbedaan kemampuan komunikasi verbal dari setiap tahapan perlakuan PECS menggunakan analisis Dwi Ragam (Analysis of Covariancel ANCOVA) untuk menyamakan kelompok perlakuan secara statistik berdasarkan hasil nilai pra dan paska uji. Selanjutnya untuk menentukan perbedaan tingkat kecemasan berkomunikasi secara verbal pada remaja tunagrahita sebelum dan sesudah mengikuti perlakuan PECS menggunakan statistik nir parametik (Wilxocon) serta uji Mann Whitney $U$ untuk membandingkan kecemasan komunikasi verbal laki-laki dan perempuan.

\section{Hasil}

Berdasarkan hasil penilaian setiap tahap perlakuan, terlihat bahwa terjadi peningkatan keterampilan komunikasi verbal pada setiap aktivitas tahapan perlakuan PECS yang diikuti oleh remaja tunagrahita jenjang SD. (Tabel 1).

Berdasarkan analisis Dwi Ragam terlihat bahwa terjadi kecenderungan peningkatan keterampilan komunikasi verbal siswa siswi mulai tahap dua sampai dengan tahap lima. Sedangkan peningkatan keterampilan komunikasi verbal yang signifikan terjadi pada tahap enam (Tabel 2).

Sedangkan berdasarkan hasil uji $\mathrm{t}$ Contoh Berpasangan untuk tingkat kecemasan komunikasi verbal remaja tunagrahita jenjang SD menunjukkan bahwa tingkat kecemasan komunikasi verbal remaja tunagrahita berbeda nyata (Uhit > p 5\%=0,31 >0,05) (Tabel 3). 
SUNUSI, DKK.

Tabel 1

Hasil penilaian tahap 1 sampai tahap 6 PECS pada remaja tunagrahita jenjang SD

\begin{tabular}{|c|c|c|c|c|c|c|c|c|c|c|c|c|c|c|}
\hline \multirow{3}{*}{$\mathbf{R}$} & \multicolumn{12}{|c|}{ Tahapan Perlakuan } & \multirow{2}{*}{\multicolumn{2}{|c|}{ Total }} \\
\hline & \multicolumn{2}{|c|}{1} & \multicolumn{2}{|c|}{2} & \multicolumn{2}{|c|}{3} & \multicolumn{2}{|c|}{4} & \multicolumn{2}{|c|}{5} & \multicolumn{2}{|c|}{6} & & \\
\hline & $\mathrm{X}$ & $\mathrm{Y}$ & $\mathrm{X}$ & $\mathbf{Y}$ & $x$ & $\bar{Y}$ & $\mathrm{X}$ & $\mathrm{Y}$ & $\mathrm{X}$ & $\mathbf{Y}$ & $\mathrm{X}$ & 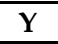 & $X$ & $Y$ \\
\hline $\mathrm{R}_{1}$ & 1 & 4 & 4 & 6 & 6 & 11 & 11 & 12 & 12 & 14 & 14 & 20 & 48 & 67 \\
\hline $\mathrm{R}_{2}$ & 1 & 3 & 3 & 3 & 3 & 11 & 11 & 12 & 12 & 14 & 14 & 20 & 44 & 63 \\
\hline $\mathrm{R}_{3}$ & 1 & 3 & 3 & 3 & 3 & 7 & 7 & 9 & 9 & 10 & 10 & 20 & 33 & 52 \\
\hline $\mathrm{R}_{4}$ & 1 & 4 & 4 & 6 & 6 & 11 & 11 & 12 & 12 & 14 & 14 & 20 & 48 & 67 \\
\hline $\mathrm{R}_{5}^{*}$ & 1 & 4 & 4 & 6 & 6 & 11 & 11 & 12 & 12 & 14 & 14 & 20 & 48 & 67 \\
\hline $\mathrm{R}_{6}$ & 1 & 4 & 4 & 6 & 6 & 11 & 11 & 12 & 12 & 14 & 14 & 20 & 48 & 67 \\
\hline $\mathrm{R}_{7}^{*}$ & 1 & 4 & 4 & 6 & 6 & 11 & 11 & 9 & 9 & 10 & 10 & 15 & 41 & 55 \\
\hline Total & 7 & 26 & 26 & 36 & 36 & 73 & 73 & 78 & 78 & 90 & 90 & 135 & 310 & 438 \\
\hline
\end{tabular}

Keterangan: $\mathrm{R}=$ Responden/Remaja tunagrahita jenjang SD; $\mathrm{X}=$ Pra Uji; Y = Paska Uji; ${ }^{*}$ = Perempuan.

Tabel 2

Hasil uji tahapan perlakuan PECS pada remaja tunagrahita jenjang SD

\begin{tabular}{lcccccc}
\hline & \multicolumn{7}{c}{ Tahapan Perlakuan } \\
\cline { 2 - 7 } & $\mathbf{1}$ & $\mathbf{2}$ & $\mathbf{3}$ & $\mathbf{4}$ & $\mathbf{5}$ & $\mathbf{6}$ \\
\hline Rataan & 7,226 & 7,338 & 9,411 & 10,720 & 11,699 & 16,175 \\
W=4,448 & (a) & $(\mathbf{a b})$ & $(\mathbf{a b})$ & (ab) & (b) & (c) \\
\hline
\end{tabular}

Keterangan: $\mathrm{W}=$ Nilai beda nyata jujur dengan tingkat kebermaknaan $5 \%$.

Angka-angka yang di ikuti dengan huruf yang sama menunjukkan antar tahapan perlakuan tidak berbeda nyata, sebaliknya angka-angka yang diikuti dengan huruf yang berbeda menunjukkan antar tahapan perlakuan berbeda nyata.

Tabel 3

Hasil uji beda tingkat kecemasan komunikasi verbal remaja tunagrahita sebelum dan sesudah perlakuan

\begin{tabular}{lccccc}
\hline \multicolumn{1}{c}{ Perlakuan } & n & Rataan & $\mathbf{\pm S E}$ & Uhit $_{\text { }}$ & p 5\% \\
\hline Sebelum & 7 & 67,86 & 3,44 & \multirow{2}{*}{0,31} & 0,05 \\
Sesudah & & 69,57 & 3,22 & & \\
\hline
\end{tabular}

Hasil uji $\mathrm{t}$ untuk tingkat kecemasan komunikasi verbal remaja tunagrahita jenjang SD berdasarkan jenis kelamin menunjukkan bahwa kecemasan komunikasi verbal pada remaja tunagrahita lakilaki maupun perempuan berbeda nyata $\left(\mathrm{U}_{\text {hit }}>\right.$ p $\left.5 \%=0,35>0,05\right)($ Tabel 4).

\section{Diskusi}

PECS dapat meningkatkan keterampilan komunikasi verbal remaja tunagrahita jenjang SD. Sebagian remaja SD di SLB Negeri Salatiga yang mengikuti pelatihan tidak bisa membaca sehingga pelatihan
PECS yang menggunakan bahan gambar memudahkan dan menyenangkan remaja melakukan pertukaran nama hanya dengan melihat gambar saja. Hal tersebut sesuai dengan pernyataan Rusman (2009) bahwa anak-anak disabilitas lebih mudah menggunakan visual learner, yaitu merasa senang dan lebih mudah mencerna informasi yang dapat dilihat daripada yang hanya didengar. Selain itu, Anggraini (2016) juga menambahkan bahwa media visual memiliki peranan yang sangat penting dalam proses belajar, dapat memperlancar pemahaman, memperkuat ingatan, serta dapat menumbuhkan minat siswa. 
Tabel 4

Hasil uji beda tingkat kecemasan komunikasi verbal remaja tunagrahita laki-laki dan perempuan jenjang SD

\begin{tabular}{|c|c|c|c|c|c|}
\hline Jenis Kelamin & $\mathbf{n}$ & Rataan & $\pm \mathrm{SE}$ & $U_{\text {hit }}$ & p 5\% \\
\hline Laki-laki & 5 & 71,80 & 3,93 & \multirow{2}{*}{0,35} & \multirow{2}{*}{0,05} \\
\hline Perempuan & 2 & 64 & 0 & & \\
\hline
\end{tabular}

Remaja tunagrahita yang mengikuti pelatihan metode PECS tergolong remaja tunagrahita ringan sehingga masih dalam kriteria tunagrahita mampu didik dengan tingkat IQ 55 - 69. Semua remaja tunagrahita mampu menyelesaikan metode PECS sampai pada fase enam. Hal ini sesuai dengan pernyataan Somantri (2006) bahwa tunagrahita ringan tergolong tunagrahita yang mampu dididik dan dilatih, lebih mudah diajak berkomunikasi, dan mampu mengurus diri sendiri, karena itu tunagrahita ringan tidak memerlukan pengawasan ekstra hanya perlu terus dilatih dan dididik. Humaira (2012) juga menambahkan bahwa anak tunagrahita ringan adalah anak tunagrahita yang mampu dididik secara minimal dalam bidang akademis dan memiliki kemampuan yang dapat dikembangkan, seperti membaca, menulis, mengeja, dan menghitung.

Hasil penelitian ini serupa dengan hasil penelitian Rehfeldt \& Root (2005) bahwa terjadi peningkatan keterampilan berkomunikasi pada tiga tunagrahita yang mengalami gangguan berkomunikasi dengan metode PECS. Sesuai juga dengan penelitian Stoner, et al. (2006) bahwa PECS adalah salah satu tehnik yang dapat digunakan untuk meningkatkan kemampuan komunikasi fungsional dan memperluas temuan sebelumnya pada orang dewasa yang tidak memiliki sistem komunikasi fungsional.

Selain dapat meningkatkan keterampilan komunikasi verbal, PECS juga dapat menurunkan kecemasan komunikasi verbal remaja tunagrahita jenjang SD baik pada remaja tunagrahita laki-laki maupun perempuan. PECS merupakan metode pelatihan yang menggunakan gambar namun pada tahap empat, lima, dan enam, diajarkan untuk memulai menyusun kalimat sampai dengan menanggapi pertanyaan. Pada tahap empat, lima, dan enam membutuhkan komunikasi verbal timbal balik antara peneliti dan responden tidak hanya sekedar memilih gambar, spontanitas, dan pertukaran nama sehingga pada pelaksanaannya tahap ini dilakukan berulang-ulang agar remaja tunagrahita dapat berkomunikasi verbal secara maksimal. Pada fase inilah remaja tunagrahita memulai percakapan dengan spontan tanpa ada perasaan takut ataupun cemas. Hal ini didukung pernyataan Lumbantobing (2006) bahwa remaja tunagrahita sudah dapat menguasai kecakapan sosial dan vokasional cukup untuk sehari-hari dimana kemampuan ini bisa saja hilang atau berhenti begitu saja di pertengahan jika tidak dibimbing dan diarahkan. Nida (2013) juga menambahkan bahwa tunagrahita dapat belajar berbicara dengan cara yang sama seperti pada anak umumnya tetapi mereka belajarnya lebih lambat dan memerlukan dorongan dengan cara sewajarnya sesuai tingkat perkembangan mereka.

Dalam pelaksanaan pelatihan PECS, terdapat beberapa penguatan positif bagi remaja tunagrahita yang dapat mengikuti tahapan perlakuan dengan baik, berupa 
pujian verbal, seperti "itu benar" dan "pilihan yang baik". Penguatan positif ini dapat meningkatkan kepercayaan diri remaja tunagrahita dalam melakukan komunikasi verbal tanpa ada perasaan cemas yang timbul. Hal ini sesuai dengan pernyataan Dzioba (2014) bahwa orangorang yang takut berkomunikasi verbal akan membatasi interaksi sosial mereka sehingga penguatan positif sangat diperlukan untuk memperkuat hubungan kecemasan komunikasi verbal dengan interaksi sosial seseorang. Hal ini terlihat pada saat penelitian, remaja tunagrahita sudah merasa lebih leluasa dalam berkomunikasi secara verbal.

\section{Kesimpulan}

Berdasarkan hasil dan diskusi di atas, maka peneliti menyimpulkan bahwa PECS dapat meningkatkan kemampuan komunikasi verbal remaja tunagrahita jenjang SD dikarenakan PECS menggunakan metode gambar dan memudahkan remaja tunagrahita jenjang SD untuk mengikuti pelatihan sehingga dapat meningkatkan keterampilan komunikasi verbalnya, dan juga remaja tunagrahita yang mengikuti pelatihan tergolong remaja tunagrahita ringan yang mampu dididik dan dilatih. Ada beda nyata tingkat kecemasan komunikasi verbal remaja tunagrahita sebelum dan sesudah perlatihan PECS maupun berdasar jenis kelamin dikarenakan remaja tunagrahita sudah dapat memulai percakapan secara spontan mulai pada tahap empat, lima, dan enam serta adanya penguatan positif dapat meningkatkan kepercayaan diri remaja tunagrahita dalam berkomunikasi verbal.

\section{Saran}

Saran untuk sekolah agar meningkatkan kemampuan komunikasi verbal dan mengatasi kecemasan komunikasi verbal remaja tunagrahita yaitu sekolah perlu mempertimbangkan untuk memasukkan pelatihan metode PECS dalam rencana pembelajaran dan perlu membuat buku komunikasi untuk setiap anak agar anak dapat menggunakannya di sekolah maupun di rumah. Saran untuk peneliti selanjutnya adalah perlu mengembangkan model terapi PECS untuk mengatasi kemampuan bersosialisasi lainnya pada remaja tunagrahita.

\section{Kepustakaan}

Anggraini, V. D. (2016). Pendekatan Picture Exchange Communication System (PECS) terhadap kemampuan bicara dan komunikasi program kebutuhan khusus pada siswa autis di SLB. Skripsi (tidak dipublikasikan). Surabaya: Jurusan Pendidikan Luar Biasa, Fakultas Ilmu Pendidikan, Universitas Negeri Surabaya.

Balai Pengembangan Pendidikan Khusus (BP-DIKSUS). (2016). Data statistik siswa. Diunduh dari: http://www.bp2klk.org/v2/index.php? page=siswa/tanggal 17 Februari 2017.

Bernard-Opitz, V., Sriram, N., \& NakhodaSapuan, S. (2001). Enhancing social problem solving in children with autism and normal children through computer-assisted instruction. Journal of Autism and Developmental Disorders, 31, 377-384. doi: 10.1023/ A:1010660 502130

Beukelman, D. R, \& Mirenda, P. (2013). Augmentative and alternative communication: Supporting children and adults with complex communication needs. Baltimore, MD: Brookes.

Bondy, A., \& Frost, L. (1994). The picture exchange communication system. 
Focus on Austism and Other Developmental Disabilities, 9(3), 1-19. doi: 10.1177/108835769400900301

Bondy, A., \& Frost, L. (2011). A picture's worth: PECS and other visual communication strategi in autism (2nd ed.). Woodbine House: Library of Congress Cataloging in Publication Data.

Cummings, A. R., Carr, J. E., \& LeBlane, L. A. (2011). Experimental evaluation of the training structure of the Picture Exchange Communication System (PECS). Research in Autism Spectrum Disorder, 6, 32-45. doi: 10.1016/ j.rasd. 2011.08.006

Departemen Kesehatan Republik Indonesia (DEPKES-RI). (2010). Pedoman pelayanan kesehatan anak di Sekolah Luar Biasa (SLB). Diunduh dari: http:// www.depkes.go.id//IndonesiaNasiona 1.pdf/tanggal 17 Februari 2017.

Departemen Kesehatan Republik Indonesia. (2014). Penyandang disabilitas pada anak. Diunduh dari: http://www. depkes.go.id/resources/download/pus datin/infodatin/infodatin_disabilitas.p df/tanggal 17 Februari 2017.

Dzioba, A. (2014). Exploring communication apprehension and its relationship to communication attitude and sociocommunicative functioning in children with velopharyngeal insufficiency. London, Ontario, Canada: The School of Graduate and Postdoctoral Studies, The University of Western Ontario.

Garrison, K. R., \& Garrison, J. P. (1977). Measurement of communication apprehension among children. Paper presented at the Annual Meeting of the International Communication Association. Jerman, Berlin, 29 Mei-4 Juni.
Geniofam. (2010). Mengasuh dan mensukseskan anak berkebutuhan khusus. Yogyakarta: Gara Ilmu.

Hallahan, D. P., \& Kauffman, J. M. (2006). Exceptional learners: An introduction to special education (10th ed.). Boston: Pearson.

Hart, J. E., \& Whalon, K. J. (2008). Promote academic engagement and communication of students with autism spectrum disorder in inclusive settings. Intervention in School and Clinic, 44(3), 116-120.

Humaira, D. (2012). Pelaksanaan pembelajaran Bahasa Indonesia bagi anak tunagrahita ringan kelas III di SLB Sabiluna Pariaman. Jurnal Ilmiah Pendidikan Khusus, 1(3), 95-109.

Lumbantobing, S. M. (2006). Anak dengan mental terbelakang: Retardasi mental, gangguan belajar, gangguan pemusatan perhatian. Jakarta: Balai Penerbit FK-UI.

McCroskey, J.C. (1984). The communication apprehension perspective. Journal of Communication Quarterly, 24(1), 13-38.

Murwati, A. (2013). Meningkatkan kemampuan komunikasi meminta pada anak autis melalui media PECS (Picture Exchange Communication System). Tesis (Tidak dipublikasikan). Surakarta: Program Pendidikan Magister Psikologi Profesi Fakultas Psikologi-UMS.

Neely, L., Rispoli, M., Camargo, S., Davis, H., \& Boles, M. (2013). The effect of instructional use of an iPad on challenging behavior and academic engagement for two students with autism. Research in Autism Spectrum Disorders, 7(4), 509-516. 


\section{SUNUSI, DKK.}

Nida, F. L. K. (2013). Komunikasi bagi anak berkebutuhan khusus. Jurnal Komunikasi Penyiaran Islam, 1(2), 163189.

Rehfeldt, R. A., \& Root, S. L. (2005). Establishing derived requesting skills in adults with severe developmental disabilities. Journal of Applied Behavior Analysis, 38, 101-105. doi: 10.1901/ jaba.2005.106-03

Ruslan, R. (2008). Manajemen public relations and media komunikasi. Jakarta: PT. Raja Grafindo Persada.

Rusman. (2009). Manajemen kurikulum. Jakarta: Rajawali Press.

Santrock, J. W. (2007). Child development (11th ed.). Jakarta: Erlangga.
Somantri, S. (2006). Psikologi anak luar biasa. Bandung: Refika Aditama.

Stoner, J. B., Beck, A. R., Bock, S. J., Hickey, K., Kosuwan, K., \& Thompson, J. R. (2006). The effectiveness of the picture exchange communication system with non-speaking adults. Remedial and Special Education, 27(3), 154-165.

Weiten, W., Lloyd, M., Dunn, D., \& Hammer, E. (2009). Psychology applied to modern life. USA: Wadsworth Cengange Learning.

West, R., \& Turner, L. H. (2009). Teori komunikasi. Jakarta: Salemba Humanika. 